\title{
Program compliance, weight loss and health profile changes in WHO obesity classes after very low energy dietary intervention
}

\author{
Thomas G Wright ${ }^{1,2^{*}}$, Brian Dawson ${ }^{2}$, Geoffrey Jalleh ${ }^{3}$ and Kym J Guelfi ${ }^{2}$ \\ *Correspondence: gwright@optimumhms.com.au \\ 'Optimum Clinic, Perth, Australia. \\ ${ }^{2}$ School of Sports Science, Exercise and Health, University of Western Australia, Australia. \\ ${ }^{3}$ Centre for Behavioural Research in Cancer Control, Curtin University, Perth, Australia.
}

\begin{abstract}
Background: To assess program compliance, weight loss and health benefits in different WHO obesity classes (Class I: BMI 3034.9; Class II: BMI 35.0-39.9; Class III: BMI 40+) after a very low energy diet intervention.

Methods: Obese participants $(n=1012)$ attending a private weight control clinic enrolled in a 26 week program. The first 12 weeks involved restricted energy intake ( $800 \mathrm{kcal} / \mathrm{day})$, then gradual reintroduction of normal food (1200-1300 kcal/day), in conjunction with behaviour management. Body mass index (BMI), body mass, girths, blood pressure, cholesterol, triglycerides and glucose were measured before, during and after the 26 week intervention. Low compliance was defined as completing only 1-12 weeks, medium compliance 13-20 weeks and high compliance 21-26 weeks of the program.

Results: Overall, 52\% of participants achieved high compliance. Greater compliance resulted in greater weight loss and health profile changes across all obesity classes. With high compliance, for Class I, II and III groups respectively, 79, 77 and $79 \%$ lost $15 \%$ or more of initial body mass. Class III participants had greater reductions in body mass and most measured health markers than Class I and II persons.

Conclusion: Higher program compliance is associated with greater weight reduction and health profile benefits in all WHO obesity classes, with larger changes occurring in the Class III group.
\end{abstract}

Keywords: BMI, very low energy diet, WHO obesity classes, compliance

\section{Introduction}

Worldwide, approximately 1.5 billion adults are overweight, including approximately 500 million who are obese [1]. By gender, it has been reported that $19 \%$ of males and $22 \%$ of females are obese [2]. Obesity is defined as a body mass index $(\mathrm{BMI})>30 \mathrm{~kg} / \mathrm{m}^{2}$. There is further segmentation of the obese into World Health Organisation (WHO) Class I (BMI $30-34.9 \mathrm{~kg} /$ $\mathrm{m}^{2}$ ), Class II (BMI 35-39.9 kg/ $\mathrm{m}^{2}$ ) and Class III (BMI 40+ kg/ $\mathrm{m}^{2}$ ) $[1,7]$. The disease burden associated with obesity brings high national health care costs $[2-4,6]$. For example, annual healthcare costs in Australia in 2009 for obese individuals were reported to be \$6693AUD, compared to \$4658AUD for normal weight individuals [5], and a BMI of $>40$ (Class III obesity) was previously estimated to double the health care costs of persons of normal weight [9]. Importantly, moving an obese individual from a higher obesity class to a lower class can also bring substantial savings in health care costs [9].

A common treatment for obesity is a very low energy diet (VLED) and these have been researched since the 1920's [19-23]. Studies utilising VLED's commonly report significant weight loss and improved cardiovascular risk factors $[13,23,24]$. Clinical use of a VLED has usually been in small groups [19], with $\mathbf{7 0 - 8 0 \%}$ of participants being females $[\mathbf{2 2 , 2 4 , 2 6 ]}$. Usually, greater program compliance is associated with greater weight loss $[\mathbf{1 8}, \mathbf{2 4}]$, and greater weight loss is associated with greater economic benefits $[5,9]$. We have previously shown the impact of increased compliance to a commercial weight loss program on weight loss for different genders $[17,18]$. However, the WHO obesity classes, which are not separated by gender, but which are commonly used to profile obese populations, have not commonly been used to report weight and health changes after weight control programs. Further, a lack of research evaluating commercial weight loss programs has recently been emphasised [19]. Therefore, the aim of this study was to investigate the effect of program compliance on weight loss and health profile changes in different WHO classes of obese individuals, using a VLED, while attending a private fee for service weight management clinic in Perth, Western Australia. It was hypothesised that weight loss and health benefits would be greater with better compliance and that Class III obesity individuals would achieve greater absolute changes than Class I or II.

\section{Methods}

The files (non-identifying) of obese females $(n=734)$ and males $(n=308)$ were retrospectively analysed and separated into obesity classes - Class I ( $n=323)$, Class II $(n=353)$ and Class III $(n=326)$, by arrangement with the clinic. Program entry required a BMI 
Wright et al. Global Epidemic Obesity 2013,

Table 1. Mean $( \pm \mathrm{SD})$ sample characteristics (mixed gender) for Obese Classes I, II and III, separated into program compliance categories.

\begin{tabular}{lcccc}
\hline Compliance & 1-12 weeks & 13-20 weeks & 21-26 weeks & Total \\
\hline CLASS I & $(\mathrm{n}=65)$ & $(\mathrm{n}=111)$ & $(\mathrm{n}=157)$ & $(\mathrm{n}=333)$ \\
$($ BMI 30-34.9 kg/m²) & & & & \\
\hline Age $(\mathrm{y})$ & $41.5 \pm 12.2$ & $41.9 \pm 10.2$ & $44.8 \pm 11.3$ & $43.2 \pm 11.2$ \\
Weight $(\mathrm{kg})$ & $93.6 \pm 11.5$ & $93.4 \pm 10.0$ & $95.1 \pm 10.6$ & $94.2 \pm 10.6$ \\
Height $(\mathrm{cm})$ & $168.7 \pm 9.3$ & $169.0 \pm 8.4$ & $169.4 \pm 8.5$ & $169.2 \pm 8.6$ \\
\hline CLASS II & $(\mathrm{n}=65)$ & $(\mathrm{n}=88)$ & $(\mathrm{n}=200)$ & $(\mathrm{n}=353)$ \\
$($ BMI 35.0-39.9 kg/m $)$ & & & & \\
\hline Age $(\mathrm{y})$ & $40.6 \pm 12.7$ & $43.5 \pm 11.0$ & $42.8 \pm 10.5$ & $42.6 \pm 11.1$ \\
${ }^{1}$ Weight $(\mathrm{kg})$ & $108.1 \pm 13.0$ & $107.2 \pm 12.4$ & $106.2 \pm 12.4$ & $106.8 \pm 12.5$ \\
Height $(\mathrm{cm})$ & $170.2 \pm 9.1$ & $169.3 \pm 9.2$ & $168.9 \pm 9.2$ & $169.3 \pm 9.2$ \\
\hline CLASS III & $(\mathrm{n}=68)$ & $(\mathrm{n}=88)$ & $(\mathrm{n}=170)$ & $(\mathrm{n}=326)$ \\
$\left(\right.$ BMI 40+ kg/m $\left.{ }^{2}\right)$ & & & & \\
\hline Age $(\mathrm{y})$ & $41.2 \pm 10.2$ & $42.3 \pm 11.8$ & $42.2 \pm 10.8$ & $42.0 \pm 10.9$ \\
${ }^{2}$ Weight $(\mathrm{kg})$ & $127.3 \pm 18.3$ & $128.8 \pm 20.9$ & $129.4 \pm 22.4$ & $128.8 \pm 21.1$ \\
Height $(\mathrm{cm})$ & $168.6 \pm 9.0$ & $169.2 \pm 9.4$ & $168.7 \pm 9.2$ & $168.8 \pm 9.2$ \\
\hline
\end{tabular}

${ }^{1} \mathrm{p}=0.000$ between Class II vs Class I for all compliance categories. ${ }^{2} \mathrm{p}=0.000$ between Class III vs Class I and Class II respectively, for all compliance categories.

$\geq 30 \mathrm{~kg} / \mathrm{m}^{2}$, with no contraindications to treatment: namely, recent myocardial infarction or major surgery, current steroid use, eating disorders, type 1 diabetes mellitus, pregnancy, lactose intolerance and certain medications. Clinic entry was by self referral or from a friend, or by their general practitioner. All participants had given informed consent, allowing their data to be used for research and agreement to undertake the program. The University of Western Australia Research Ethics Committee granted approval for the study.

Before beginning the program, participants were medically evaluated by the clinic doctor, including medical history, resting $E C G$, urinalysis and fasting blood biochemistry profile. Blood samples were taken (after a 12-hour overnight fast) for cholesterol, triglyceride and glucose levels and were analysed at the same pathology laboratory. All participants set out to attend the clinic for 26 consecutive weeks, but could withdraw at any stage. They all received the same treatment program in small groups of 8-10, delivered by a multidisciplinary team of health professionals. The general program design was first reported in a previous VLED study [26]. This original design was further modified to suit the unique conditions of the clinic, complying with Australian guidelines [27].

During the program, participants attended the clinic weekly, when they were weighed, had their blood pressure measured and completed a standard questionnaire which assessed their health status, including bowel health, water consumption patterns and general wellbeing. At this meeting they also self reported on their compliance to the recommended meal plans for the previous week and were given appropriate reinforcement and encouragement. They then participated in a 60-75 min small group session as part of a structured 26week educational and behaviour management program, in which no new member joined the group after week 2 in the program. The behaviour management components covered the core areas of assertion, stress management, goal setting, self monitoring, portion control, problem solving, cognitive restructuring, relapse prevention, optimistic thinking and self care. These groups were led by physical and health educators (week 1-8, 23-26), a registered psychologist (week 9-12), dietician (week 13-20) or exercise physiologist (week 4-5, 21-22). All groups followed the program manual that was supplied to each participant $[17,18]$.

For the first 12 weeks of the program, participants replaced all normal food and fluids (other than water) with Optifast 800 (Nestle $\odot)$, providing $800 \mathrm{kcal}(3360 \mathrm{~kJ})$ per day (70 of protein, $13 \mathrm{~g}$ of fat, $100 \mathrm{~g}$ of carbohydrate) and $100 \%$ of the recommended daily allowance of vitamins, minerals and essential elements. During weeks 13-20, normal food gradually replaced the number of VLED sachets used weekly. By week 20 , all participants were consuming 1100-1200 kcal daily by normal food, within a structured eating plan. Weeks 21-26 were maintenance, with participants consuming 1200-1300 $\mathrm{kcal} /$ day. During weeks 1-20, participants were examined weekly by the clinic doctor and nurse, with the full medical evaluation again performed in week 26 . Blood measures were taken in weeks 1,12, 20 and 26 only.

Body mass was measured on a battery powered, Wellsweigh electronic scale $( \pm 100 \mathrm{~g}$, maximum load $200 \mathrm{~kg})$. Resting blood pressure (BP) were measured on the right arm while seated, using a mercury column sphygmomanometer. Girths (waist and hip) were measured at specific anatomical markers (umbilicus level and largest diameter around gluteus maximus) with a standard $2 \mathrm{~m}$ long tape [28]. Height was measured with participants standing in an erect, relaxed manner with their back against a SECA (model 216) wall mounted device. Height and mass were then used for calculation of BMI $\left(\mathrm{kg} / \mathrm{m}^{2}\right)$ and obesity class classification.

Data was calculated as proportion or mean \pm SD. Independent and dependent $t$ tests were used, with signi-ficance accepted at $p<0.05$. Program compliance was defined as low if participants completed only weeks 1-12, medium (completion of weeks 13-20) or high (completion of weeks 21-26). Odds ratios were calculated on each obesity class for participants who lost $15 \%$ or more of their initial body mass. Unfortunately, there was no opportunity to track the participants for follow up data once they had completed the 26 week program.

\section{Results}

Baseline characteristics of the sample, separated by program compliance categories and obesity classes, are shown in Table 1. Class II participants had a significantly higher body mass than class I individuals, and class III participants had a higher body mass than class I and II individuals. Overall, 52\% $(n=594)$ of participants had high compliance, completing 21-26 weeks of the program, $28 \%(n=320)$ had medium compliance (completed 13-20 weeks) and 20\% ( $n=208)$ had 
Wright et al. Global Epidemic Obesity 2013,

Table 2. Weight loss as a percentage of initial weight for Obesity Classes I, II and III, separated into program compliance categories and shown as percentage of sample.

\begin{tabular}{|c|c|c|c|c|}
\hline Weight loss (\%) & 1-12 weeks & 13-20 weeks & 21-26 weeks & Total \\
\hline CLASS I & $(n=65)$ & $(\mathrm{n}=111)$ & $(n=157)$ & $(n=333)$ \\
\hline$<10.00$ & 73.8 & 21.6 & 5.1 & 24.0 \\
\hline $10.01-15.00$ & 20.0 & 27.9 & 15.9 & 20.7 \\
\hline $15.01-20.00$ & 6.2 & 33.3 & 34.4 & 28.5 \\
\hline $20.01-25.00$ & 0.0 & 13.5 & 31.2 & 19.2 \\
\hline $25.01-30.00$ & 0.0 & 2.8 & 12.1 & 6.7 \\
\hline $30.01+$ & 0.0 & 0.9 & 1.3 & 0.9 \\
\hline Total & 100.0 & 100.0 & 100.0 & 100.0 \\
\hline CLASS II & $(n=65)$ & $(\mathbf{n}=\mathbf{8 8})$ & $(n=200)$ & $(\mathrm{n}=353)$ \\
\hline$<10.00$ & 52.3 & 21.6 & 4.0 & 17.3 \\
\hline $10.01-15.00$ & 38.5 & 20.5 & 19.0 & 22.9 \\
\hline $15.01-20.00$ & 9.2 & 27.2 & 28.0 & 24.4 \\
\hline $20.01-25.00$ & 0.0 & 25.0 & 31.0 & 23.8 \\
\hline $25.01-30.00$ & 0.0 & 5.7 & 16.0 & 10.5 \\
\hline $30.01+$ & 0.0 & 0.0 & 2.0 & 1.1 \\
\hline Total & 100.0 & 100.0 & 100.0 & 100.0 \\
\hline CLASS III & $(n=68)$ & $(\mathbf{n}=\mathbf{8 8})$ & $(\mathrm{n}=170)$ & $(\mathrm{n}=326)$ \\
\hline$<10.00$ & 64.7 & 23.9 & 5.9 & 23.0 \\
\hline $10.01-15.00$ & 22.1 & 20.5 & 15.3 & 18.1 \\
\hline $15.01-20.00$ & 5.9 & 23.9 & 27.6 & 22.1 \\
\hline $20.01-25.00$ & 5.8 & 19.3 & 26.5 & 20.2 \\
\hline $25.01-30.00$ & 1.5 & 11.3 & 15.9 & 11.7 \\
\hline $30.01+$ & 0.0 & 1.1 & 8.8 & 4.9 \\
\hline Total & 100.0 & 100.0 & 100.0 & 100.0 \\
\hline
\end{tabular}

low compliance (completed 1-12 weeks). Compliance was similar between obesity classes; for high compliance, 47\% of Class I ( $n=157), 57 \%$ of Class II ( $n=200)$ and $52 \%$ of Class III $(n=170)$ completed 21-26 weeks, for medium compliance, $33 \%$ of Class I ( $n=111), 25 \%$ of Class II ( $n=88)$ and $27 \%$ of Class III $(n=88)$ completed 13-20 weeks and for low compliance, $20 \%$ of Class I ( $n=65), 18 \%$ of Class II ( $n=65)$ and $21 \%$ of Class III ( $n=68)$ completed 1-12 weeks.

Weight loss as a percentage of initial weight is shown in Table 2. Of note, 79\% (Class I), 77\% (Class II) and 79\% (Class III) of high compliance participants respectively lost $15 \%$ or more of initial weight, compared to $50 \%, 58 \%$ and $56 \%$ for medium compliance participants and only $6 \%, 9 \%$ and $13 \%$ for low compliance participants. In absolute terms, mean weight loss approximated $7 \mathrm{~kg}, 14 \mathrm{~kg}$ and $18 \mathrm{~kg}$ with low, medium and high compliance for Class I, compared to $10 \mathrm{~kg}, 17 \mathrm{~kg}$ and $21 \mathrm{~kg}$ with low, medium and high compliance for Class II and $11 \mathrm{~kg}, 21 \mathrm{~kg}$ and $27 \mathrm{~kg}$ for low, medium and high compliance for Class III. The effect of the intervention on other health variables is shown in Table 3. Overall, BP decreased following the intervention in all classes of obesity, at all compliance levels. Blood cholesterol, triglyceride and glucose levels also reduced across all classes of obesity, but significant changes required medium or high compliance (Table 3 ).

Table 4 shows the odds ratios calculated for all three classes. For weight loss of greater than $15 \%$ of initial weight, the effect of greater compliance is clearly seen. For medium compliance (compared to low) participants were 4.1-13.6 times more likely to lose $>15 \%$ of initial weight, and for high compliance 24.4 57.3 times more likely, across all obesity classes.

\section{Discussion}

With worldwide obesity levels continuing to rise $[1,5,11,13]$, the research evaluation of different types of commercial intervention programs is vitally important [19]. As increases in obesity classes are strongly associated with higher health care costs [9], for medical practitioners and other health professionals working in the area of obesity, research data on specific weight loss regimes and private clinic programs [14-18] may assist in counselling obese individuals and potentially lead to significant health care savings.

Despite the existence and widespread application of the WHO obesity classes, little use of these has been made in research studies for reporting weight loss in obese participants. We have previously reported on the positive effect of greater compliance to weight control programs in men and women $[17,18]$, but were interested to see if the same magnitude of effect was present when WHO obesity classes, which are gender neutral, were used to separate obese participants. Unsurprisingly, our results demonstrate that greater program compliance, irrespective of the initial class of obesity, produces better weight and health outcomes. Within all three classes of obesity, greater weight loss as a percentage of entry weight was recorded in those who complied better. Class III individuals with greater compliance recorded the greatest absolute weight change of any category. Notwithstanding this, compliance was similar in all three classes of obesity, and again serves to emphasise that this is a key factor in any weight control program, regardless of the entry weight and obesity class. The results here also show a consistent trend for greater positive changes in health measures such as BP, waist and hip girths and blood cholesterol, triglyceride and glucose levels with higher compliance and class of obesity. In particular, high compliance was generally found to result in more consistent changes in blood cholesterol, triglyceride and glucose levels than low compliance, especially in class II and III obese persons. These primary risk factor changes offer further motivation to comply with the weight control program for obese individuals, and can assist clinicians with counselling strategies. These health profile changes can also offer an additional point of reference for measuring success in weight management programs. These findings mirror those of other studies that have used similar VLED weight control programs over 3-6 month periods, but with separate groups of male and female obese participants $[17,18,22,24,29,30]$. The magnitude of weight loss $(\sim 20-25 \mathrm{~kg}+)$ and reduction in BMI 
Wright et al. Global Epidemic Obesity 2013,

http://www.hoajonline.com/journals/pdf/2052-5966-1-4.pdf

doi: $10.7243 / 2052-5966-1-4$

Table 3. Mean body weight, girths and health status measures for Obesity Classes I, II and III completing 1-12, 13-20 and 21-26 weeks of a weight loss program.

\begin{tabular}{|c|c|c|c|c|c|c|c|c|c|}
\hline \multirow{2}{*}{ CLASS I } & \multicolumn{3}{|c|}{ 1-12 weeks } & \multicolumn{3}{|c|}{ 13-20 weeks } & \multicolumn{3}{|c|}{ 21-26 weeks } \\
\hline & $n$ & Before & After & $\mathrm{n}$ & Before & After & $\mathrm{n}$ & Before & After \\
\hline Weight (kg) & 65 & 93.6 & $86.5^{3}$ & 111 & 93.4 & $79.8^{3 a}$ & 157 & 95.1 & $77.1^{3 b c}$ \\
\hline Initial BMI $\left(\mathrm{kg} / \mathrm{m}^{2}\right)$ & 30 & 33.0 & $30.7^{3}$ & 84 & 32.6 & $27.7^{3 \mathrm{a}}$ & 145 & 33.0 & $26.6^{3 \mathrm{bc}}$ \\
\hline Waist (cm) & 11 & 99.2 & $91.9^{3}$ & 61 & 98.9 & $86.9^{3 \mathrm{a}}$ & 141 & 101.7 & $86.0^{3 \mathrm{bc}}$ \\
\hline Hip $(\mathrm{cm})$ & 11 & 113.5 & $109.0^{3}$ & 61 & 115.0 & $104.9^{3 a}$ & 141 & 116.2 & $103.0^{3 \mathrm{bc}}$ \\
\hline Waist/hip ratio & 11 & 0.87 & 0.84 & 61 & 0.86 & $0.83^{3}$ & 141 & 0.88 & $0.84^{3}$ \\
\hline Systolic BP (mmHg) & 54 & 126.0 & $119.2^{2}$ & 107 & 129.0 & $123.6^{3}$ & 153 & 131.1 & $119.9^{3 \mathrm{c}}$ \\
\hline Diastolic BP (mmHg) & 42 & 77.9 & $74.1^{1}$ & 95 & 82.7 & $77.6^{3}$ & 145 & 82.6 & $74.0^{3 \mathrm{c}}$ \\
\hline Cholesterol (mmol/L) & 5 & 6.76 & $5.66^{1}$ & 62 & 5.72 & $5.11^{3}$ & 140 & 5.72 & $5.15^{3}$ \\
\hline Triglycerides (mmol/L) & 3 & 1.70 & 1.27 & 60 & 1.39 & $0.97^{3}$ & 139 & 1.56 & $1.04^{3}$ \\
\hline Fasting glucose $(\mathrm{mmol} / \mathrm{L})$ & 38 & 5.34 & $5.00^{1}$ & 104 & 5.30 & 5.16 & 154 & 5.49 & $5.11^{3}$ \\
\hline \multirow{2}{*}{ CLASS II } & \multicolumn{3}{|c|}{ 1-12 weeks } & \multicolumn{3}{|c|}{ 13-20 weeks } & \multicolumn{3}{|c|}{ 21-26 weeks } \\
\hline & $\mathbf{n}$ & Before & After & $\mathbf{n}$ & Before & After & $\mathbf{n}$ & Before & After \\
\hline Weight (kg) & 65 & 108.1 & $98.5^{3}$ & 88 & 107.2 & $90.0^{3 \mathrm{a}}$ & 200 & 106.2 & $85.3^{3 b c}$ \\
\hline Initial BMI $\left(\mathrm{kg} / \mathrm{m}^{2}\right)$ & 33 & 37.0 & $33.5^{3}$ & 66 & 37.2 & $30.8^{3 \mathrm{a}}$ & 185 & 37.1 & $29.8^{3 \mathrm{bc}}$ \\
\hline Waist $(\mathrm{cm})$ & 10 & 107.9 & $99.7^{3}$ & 48 & 111.3 & $97.9^{3}$ & 178 & 109.7 & $92.6^{3 \mathrm{bc}}$ \\
\hline Hip $(\mathrm{cm})$ & 10 & 120.0 & $113.8^{3}$ & 48 & 122.4 & $111.6^{3 \mathrm{a}}$ & 177 & 123.6 & $109.3^{3 \mathrm{bc}}$ \\
\hline Waist/hip ratio & 10 & 0.90 & $0.88^{1}$ & 48 & 0.91 & $0.88^{3}$ & 177 & 0.89 & $0.85^{3}$ \\
\hline Systolic BP (mmHg) & 60 & 134.3 & $125.0^{3}$ & 84 & 131.6 & $118.7^{3}$ & 196 & 133.0 & $121.5^{3}$ \\
\hline Diastolic BP (mmHg) & 53 & 83.9 & $80.0^{1}$ & 74 & 83.3 & $77.6^{3}$ & 185 & 84.9 & $76.8^{3 \mathrm{~b}}$ \\
\hline Cholesterol (mmol/L) & 15 & 5.56 & 5.57 & 51 & 5.71 & $5.21^{3 a}$ & 186 & 5.54 & $4.97^{3 \mathrm{~b}}$ \\
\hline Triglycerides (mmol/L) & 15 & 2.17 & 1.67 & 51 & 1.68 & $1.21^{3}$ & 182 & 1.62 & $1.05^{3}$ \\
\hline Fasting glucose (mmol/L) & 53 & 5.29 & 5.32 & 81 & 5.53 & $5.17^{3 \mathrm{a}}$ & 195 & 5.49 & $5.10^{3 \mathrm{~b}}$ \\
\hline \multirow{2}{*}{ CLASS III } & \multicolumn{3}{|c|}{ 1-12 weeks } & \multicolumn{3}{|c|}{ 13-20 weeks } & \multicolumn{3}{|c|}{ 21-26 weeks } \\
\hline & $\mathbf{n}$ & Before & After & $\mathbf{n}$ & Before & After & $\mathbf{n}$ & Before & After \\
\hline Weight (kg) & 68 & 127.3 & $116.1^{3}$ & 88 & 128.8 & $108.3^{3 a}$ & 170 & 129.5 & $103.0^{3 \mathrm{bc}}$ \\
\hline Initial BMI $\left(\mathrm{kg} / \mathrm{m}^{2}\right)$ & 36 & 44.5 & $40.4^{3}$ & 63 & 45.0 & $37.6^{3 \mathrm{a}}$ & 146 & 45.4 & $36.0^{3 \mathrm{bc}}$ \\
\hline Waist $(\mathrm{cm})$ & 11 & 125.0 & $116.9^{2}$ & 42 & 123.2 & $107.1^{3 a}$ & 153 & 123.3 & $104.1^{3 \mathrm{bc}}$ \\
\hline Hip $(\mathrm{cm})$ & 11 & 138.4 & $131.9^{1}$ & 42 & 136.1 & $122.1^{3 \mathrm{a}}$ & 152 & 139.4 & $121.3^{3 \mathrm{bc}}$ \\
\hline Waist/hip ratio & 11 & 0.90 & $0.89^{1}$ & 42 & 0.91 & $0.88^{3}$ & 152 & 0.89 & $0.86^{3}$ \\
\hline Systolic BP (mmHg) & 67 & 134.1 & $127.3^{3}$ & 85 & 140.4 & $126.7^{3}$ & 168 & 138.7 & $124.8^{3 \mathrm{~b}}$ \\
\hline Diastolic BP (mmHg) & 59 & 85.8 & $80.6^{3}$ & 70 & 86.9 & $80.1^{3}$ & 163 & 85.5 & $77.3^{3}$ \\
\hline Cholesterol (mmol/L) & 5 & 5.98 & 5.26 & 41 & 5.60 & $5.21^{3}$ & 154 & 5.43 & $4.89^{3}$ \\
\hline Triglycerides $(\mathrm{mmol} / \mathrm{L})$ & 4 & 1.78 & 1.45 & 40 & 1.51 & $1.22^{1}$ & 153 & 1.50 & $1.01^{3}$ \\
\hline Fasting glucose (mmol/L) & 41 & 5.54 & 5.37 & 72 & 5.74 & 5.35 & 164 & 5.59 & $5.06^{3 \mathrm{~b}}$ \\
\hline
\end{tabular}

Before vs after: ${ }^{1} \mathrm{p}<0.05 ;{ }^{2} \mathrm{p}<0.01 ;{ }^{3} \mathrm{p}<0.001 .{ }^{\mathrm{a}} \mathrm{p}<0.0513-20$ vs $1-12 ;{ }^{\mathrm{b}} \mathrm{p}<0.05$ 21-26 vs $1-12,{ }^{\mathrm{c}} \mathrm{p}<0.05$ 21-26 vs $13-20$. 
Wright et al. Global Epidemic Obesity 2013,

Table 4. Odds ratios for various percentages of weight loss in Obesity Classes I, II and III, separated into program compliance categories (Low compliance =1-12 weeks; Medium compliance =13-20 weeks; High compliance =21-26 weeks).

\begin{tabular}{|c|c|c|c|}
\hline \multicolumn{4}{|c|}{ Class I } \\
\hline & $\begin{array}{l}\text { Low compliance } \\
n=65\end{array}$ & $\begin{array}{l}\text { Medium compliance } \\
n=111\end{array}$ & $\begin{array}{c}\text { High compliance } \\
n=157\end{array}$ \\
\hline \multicolumn{4}{|c|}{ Proportion of initial weight loss: } \\
\hline Greater than $10 \%$ & $26.2 \%$ & $78.4 \%$ & $94.9 \%$ \\
\hline Odds ratio $(95 \% \mathrm{CI})$ & 1.0 & $10.2(5.0-20.9)$ & $52.6(21.4-129.5)$ \\
\hline Greater than $15 \%$ & $6.2 \%$ & $50.5 \%$ & $79.0 \%$ \\
\hline Odds ratio $(95 \% \mathrm{CI})$ & 1.0 & $4.1(1.3-13.0)$ & $57.3(19.4-169.1)$ \\
\hline Greater than $20 \%$ & $0.0 \%$ & $17.1 \%$ & $44.6 \%$ \\
\hline Odds ratio $(95 \% \mathrm{CI})$ & - & 1.0 & $3.9(2.2-7.0)$ \\
\hline Greater than $25 \%$ & $0.0 \%$ & $3.6 \%$ & $13.4 \%$ \\
\hline Odds ratio $(95 \% \mathrm{CI})$ & - & 1.0 & $4.1(1.4-12.4)$ \\
\hline \multicolumn{4}{|c|}{ Class II } \\
\hline & $\begin{array}{l}\text { Low compliance } \\
n=65\end{array}$ & $\begin{array}{l}\text { Medium compliance } \\
\qquad \mathbf{n}=\mathbf{8 8}\end{array}$ & $\begin{array}{l}\text { High compliance } \\
\quad \mathbf{n}=\mathbf{2 0 0}\end{array}$ \\
\hline \multicolumn{4}{|c|}{ Proportion of initial weight loss: } \\
\hline Greater than $10 \%$ & $47.7 \%$ & $78.4 \%$ & $96.0 \%$ \\
\hline Odds ratio $(95 \% \mathrm{CI})$ & 1.0 & $4.0(2.0-8.0)$ & $26.3(11.2-62.1)$ \\
\hline Greater than $15 \%$ & $9.2 \%$ & $57.9 \%$ & $77.0 \%$ \\
\hline Odds ratio $(95 \% \mathrm{CI})$ & 1.0 & $13.6(5.3-34.7)$ & $32.9(13.4-81.1)$ \\
\hline Greater than $20 \%$ & $0.0 \%$ & $30.7 \%$ & $49.0 \%$ \\
\hline Odds ratio $(95 \% \mathrm{CI})$ & - & 1.0 & $2.2(1.3-3.7)$ \\
\hline Greater than $25 \%$ & $0.0 \%$ & $5.7 \%$ & $18.0 \%$ \\
\hline Odds ratio $(95 \% \mathrm{CI})$ & - & 1.0 & $3.6(1.4-9.6)$ \\
\hline \multicolumn{4}{|c|}{ Class III } \\
\hline & $\begin{array}{l}\text { Low compliance } \\
\qquad n=68\end{array}$ & $\begin{array}{l}\text { Medium compliance } \\
\quad n=88\end{array}$ & $\begin{array}{l}\text { High compliance } \\
\quad n=170\end{array}$ \\
\hline \multicolumn{4}{|c|}{ Proportion of initial weight loss: } \\
\hline Greater than $10 \%$ & $35.3 \%$ & $76.1 \%$ & $94.1 \%$ \\
\hline Odds ratio $(95 \% \mathrm{CI})$ & 1.0 & $5.8(2.9-11.8)$ & $29.3(13.0-65.9)$ \\
\hline Greater than $15 \%$ & $13.3 \%$ & $55.6 \%$ & $78.8 \%$ \\
\hline Odds ratio $(95 \% \mathrm{CI})$ & 1.0 & $8.2(3.6-18.7)$ & $24.4(11.0-53.9)$ \\
\hline Greater than $20 \%$ & $7.4 \%$ & $31.8 \%$ & $51.2 \%$ \\
\hline Odds ratio $(95 \% \mathrm{CI})$ & 1.0 & $5.9(2.1-16.2)$ & $13.2(5.1-34.4)$ \\
\hline Greater than $25 \%$ & $1.5 \%$ & $12.5 \%$ & $24.7 \%$ \\
\hline Odds ratio $(95 \%$ CI $)$ & 1.0 & $9.7(1.2-77.2)$ & $22.3(3.0-165.7)$ \\
\hline
\end{tabular}

(by $7-9 \mathrm{~kg} / \mathrm{m}^{2}$ ) found here with high compliance is similar to changes reported previously in male and female group data $[18,29,30]$. With the substantial weight loss achieved with high compliance here, it is noted that Class III obese persons reverted to Class II ( 45.4 to $36.0 \mathrm{~kg} / \mathrm{m}^{2}$ ) and Class II obese persons reverted to "overweight" ( 37.1 to $29.8 \mathrm{~kg} / \mathrm{m}^{2}$ ), as did Class I ( 33.0 to $\left.26.6 \mathrm{~kg} / \mathrm{m}^{2}\right)$. These classification changes were also largely evident with medium compliance, but not with low compliance participants.

While it was anticipated that our results would demonstrate the effectiveness of high compliance in weight loss programs, the odds ratios calculated here can provide a powerful practical message for clinicians to use when counselling obese persons. With high program compliance, Class I, II and III individuals were respectively $57.3,32.9$ and 24.4 times more likely to lose $15 \%$ or more of their initial weight than 
Wright et al. Global Epidemic Obesity 2013,

low compliance participants. A lesser, but still practically important effect was also seen with medium compliance, as Class I, II and III individuals were respectively, 4.1, 13.6 and 8.2 times more likely to lose $15 \%$ or more of initial weight when compared to low compliance participants. These odds ratios are slightly greater than those reported previously on obese males and slightly lower than for obese females [18]. Whether separated by gender or by obese class, it is clear that greater compliance has a pronounced influence on resulting weight loss and health profile changes in obese persons. Strategies to maximise compliance in weight loss programs are therefore an extremely important aspect for commercial operators and clinicians to consider.

\section{Limitations}

It is acknowledged that within 3-5 years many weight loss program participants have regressed towards or returned to their initial weight [31]. Unfortunately, no follow up on the participants used here was possible, but there is no evidence that VLED programs lead to worse long term outcomes than other weight loss treatments $[\mathbf{2 9}, \mathbf{3 2}]$. Another potential limitation is that the participants were all drawn from one clinic and could only be assessed over a 6 month period. The client base of the clinic from which the data was taken reflected a cross section of people from Perth, Western Australia who had either self selected or been referred by their GP to the clinic. Most were from higher socio-economic areas and 65\% of the total sample had private health insurance, which may partly explain the relatively normal coronary risk and health profile of these participants, with the exception of being obese.

\section{Conclusions}

For all classes of obesity, higher program compliance produced greater positive changes in mass, BMI, girths, blood pressure and triglycerides, cholesterol and glucose. Class III obesity participants, who were significantly heavier on program entry, recorded the greatest relative mass, $\mathrm{BMI}$ and girth reductions. The odds ratios calculated here for losing $>15 \%$ of initial body weight provide a simple and powerful message for clinicians to use when counselling obese persons about weight control programs: higher program compliance will produce better outcomes.

\section{Competing interests}

The authors declare that they have no competing interests.

\section{Authors' contributions}

Experimental design and data collection (Wright), Data Analysis and interpretations (Jalleh, Dawson, Wright and Guelfi), Manuscript preparation, content structure and revision (Wright, Dawson and Guelfi). Final manuscript was read and approved by all the authors.

\section{Publication history}

Editor: Javier Sanchez Perona, Spanish National Research Council, Spain.

Received: 23-Apr-2013 Revised: 05-Jul-2013

Accepted: 16-Jul-2013 Published: 26-Jul-2013

\section{References}

1. World Health Organization, Obesity and overweight: Fact sheet number 311. updated March, 2011. I Website

2. Janus ED, Laatikainen T, Dunbar JA, Kilkkinen A, Bunker SJ, Philpot B, Tideman PA, Tirimacco R and Heistaro S. Overweight, obesity and metabolic syndrome in rural southeastern Australia. Med J Aust. 2007; 187:147-52. | Article | PubMed

3. Cameron AJ, Welborn TA, Zimmet PZ, Dunstan DW, Owen N, Salmon J, Dalton M, Jolley D and Shaw JE. Overweight and obesity in Australia: the 1999-2000 Australian Diabetes, Obesity and Lifestyle Study (AusDiab). Med J Aust. 2003; 178:427-32. | Article I PubMed

4. Kopelman P. Health risks associated with overweight and obesity. Obes Rev. 2007; 8 Suppl 1:13-7. | Article I PubMed

5. Colagiuri $S$ and Caterson I. Overweight and obesity costs Australia over \$21 billion per year. accessed February 21 $1^{\text {st }}, 2010$. | Website

6. Overweight and Obesity: Implications for workplace health and safety and workers' compensation - scoping paper. Australian Government, Australian Safety and Compensation Council, August, 2008.

7. Katzmarzyk PT and Mason C. Prevalence of class I, II and III obesity in Canada. CMAJ. 2006; 174:156-7. I Article I PubMed Abstract I PubMed Full Text

8. Kaukua J, Pekkarinen T, Sane T and Mustajoki P. Health-related quality of life in WHO class II-III obese men losing weight with very-low-energy diet and behaviour modification: a randomised clinical trial. Int J Obes Relat Metab Disord. 2002; 26:487-95. | Article I PubMed

9. Andreyeva T, Sturm R and Ringel JS. Moderate and severe obesity have large differences in health care costs. Obes Res. 2004; 12:1936-43. | Article I PubMed

10. Access Economics Report to Diabetes Australia. The growing costs of obesity in $\mathbf{2 0 0 8}$ - three years on. October, 2008. I Pdf

11. Australian Bureau of Statistics (ABS). National health survey: summary of results, 2007-2008. Canberra: ABS, 2009. I Website

12. Anderson JE, Govada M, Steffen TK, Thorne CP, Varvarigou V, Kales SN and Burks SV. Obesity is associated with the future risk of heavy truck crashes among newly recruited commercial drivers. Accid Anal Prev. 2012; 49:378-84. | Article I PubMed

13. Medibank. Obesity Report. 2010. I Pdf

14. Wadden T, Volger S and Sarwer DB et al. A two year randomised trial of obesity treatment in primary care practice. The New England Journal of Medicine. 2011; 365:1969-79. | Article

15. Appel LJ, Clark JM, Yeh HC, Wang NY, Coughlin JW, Daumit G, Miller ER, 3rd, Dalcin A, Jerome GJ, Geller S, Noronha G, Pozefsky T, Charleston J, Reynolds JB, Durkin N, Rubin RR, Louis TA and Brancati FL. Comparative effectiveness of weight-loss interventions in clinical practice. $N$ Eng/ J Med. 2011; 365:1959-68. I Article I PubMed

16. Neve M, Morgan PJ, Jones PR and Collins CE. Effectiveness of web-based interventions in achieving weight loss and weight loss maintenance in overweight and obese adults: a systematic review with meta-analysis. Obes Rev. 2010; 11:306-21. | Article | PubMed

17. Wright $\mathrm{G}$, Dawson $\mathrm{B}$, Jalleh $\mathrm{G}$ and Couch $\mathrm{MH}$. A retrospective comparison of two very low energy diets on weight loss and health status in obese women completing a 26-week program. Obesity Research \& Clinical Practice. 2007; 1:281-288. | Article

18. Wright G, Dawson B, Jalleh G and Law S. Impact of compliance on weight loss and health profile in a very low energy diet program. Aust Fam Physician. 2010; 39:49-52. I Article I PubMed

19. Hamilton M and Greenway F. Evaluating commercial weight loss programmes: an evolution in outcomes research. Obes Rev. 2004; 5:217-32. | Article | PubMed

20. Howard AN. The historical development, efficacy and safety of verylow-calorie diets. Int J Obes. 1981; 5:195-208. | $\underline{\text { Article | PubMed }}$

21. Evans FA and Strang JM. A departure from the usual methods in treating obesity. 1929. Obes Res. 1995; 3:210-4. | PubMed

22. Foster GD, Wadden TA, Peterson FJ, Letizia KA, Bartlett SJ and Conill AM. A controlled comparison of three very-low-calorie diets: effects on 
Wright et al. Global Epidemic Obesity 2013,

weight, body composition, and symptoms. Am J Clin Nutr. 1992; 55:811-

7. | Article | PubMed

23. Ivkovic-Lazar T. [Treatment of extreme obesity with a very low calorie diet]. Med Pregl. 2001; 54:534-8. | PubMed

24. Anderson JW, Konz EC, Frederich RC and Wood CL. Long-term weightloss maintenance: a meta-analysis of US studies. Am J Clin Nutr. 2001; 74:579-84. | Article | PubMed

25. Adams SO, Grady KE, Wolk CH and Mukaida C. Weight loss: a comparison of group and individual interventions. J Am Diet Assoc. 1986; 86:485-90. | PubMed

26. Wadden TA and Frey DL. A multicenter evaluation of a proprietary weight loss program for the treatment of marked obesity: a five-year follow-up. Int J Eat Disord. 1997; 22:203-12. | Article | PubMed

27. National Health and Medical Research Council. Clinical practice guidelines for the management of overweight and obesity in adults. Commonwealth of Australia, 2003. | Website

28. Egger $\mathrm{G}$. The case for using waist to hip ratio measurements in routine medical checks. Med J Aust. 1992; 156:280-5. | Article | PubMed

29. Mustajoki $P$ and Pekkarinen T. Very low energy diets in the treatment of obesity. Obes Rev. 2001; 2:61-72. | Article | PubMed

30. Saris WH. Very-low-calorie diets and sustained weight loss. Obes Res. 2001; 9 Suppl 4:295S-301S. | Article | PubMed

31. Brownell KD and Jeffrey RW. Improving long term weight loss: pushing the limits of treatment. Behaviour Therapy. 1987; 18:353-374. | Article

32. Flechtner-Mors M, Ditschuneit HH, Johnson TD, Suchard MA and Adler G. Metabolic and weight loss effects of long-term dietary intervention in obese patients: four-year results. Obes Res. 2000; 8:399-402. | Article I PubMed

\section{Citation:}

Wright T G, Dawson B, Jalleh G and Guelfi K J. Program compliance, weight loss and health profile changes in WHO obesity classes after very low energy dietary intervention. Glob Epidemi Obes. 2013; 1:4.

http://dx.doi.org/10.7243/2052-5966-1-4 